\section{A educabilidade como nexo da experiência civil contemporânea: Aproximações investigativas}

\section{La educabilidad como nexo de la experiencia civil contemporánea: Aproximaciones investigativas}

\author{
Educability as a Link of \\ Contemporary Civil Experience: \\ Research Approaches
}

\section{Julio Groppa Aquino*}

* Doctor Instituto de Psicologia, Universidade de São Paulo-USP, estudios de posdoctorado Universidad de Barcelona. Profesor Titular Departamento de Filosofia da Educação e Ciências da Educação, Faculdade de Educação, Universidade de São Paulo USP, Brasil. Investigador CNPq y FAPESP. e-mail: groppaq@usp.br

\section{Resumo}

0 presente texto argumenta que a educabilidade dos cidadãos é materializada em termos de uma demanda de formação difusa e perpétua, que se converteu num vínculo fundador da existência social. Esta tese baseiase nos resultados de doze pesquisas realizadas por um grupo dedicado aos estudos foucaultianos em educação, na Faculdade de Educação da Universidade de São Paulo. Trata-se de um esforço para analisar a relação entre a governamentalidade contemporânea e certos imperativos pedagógicos em andamento em vários campos sociais.

\section{Palavras chave}

Educabilidade, educacionalização, governamentalidade, Michel Foucault

\section{Resumen}

Este texto argumenta que la educabilidad de los ciudadanos es materializada en términos de una demanda de formación difusa y perpetua, que se ha convertido en un vínculo fundador de la existencia social. Esta tesis se sustenta en los resultados de doce investigaciones realizadas por un grupo dedicado a los estudios foucaultianos en la educación, en la Facultad de Educación de la Universidad de São Paulo. Se trata de un esfuerzo por analizar la relación entre la gubernamentalidad contemporánea y ciertos imperativos pedagógicos, en curso en distintos ámbitos sociales.

\section{Palabras clave}

Educabilidad, educacionalización, gubernamentalidad, Michel Foucault

\section{Abstract}

This text argues that the educability of citizens is objectified in terms of a demand for diffuse and perpetual training, which has become a foundational link of social existence. This statement is based upon the results of twelve researches carried out by a group from the school of Education of the University of São Paulo, devoted to Foucaultian studies in education. It is an effort to analyze the relationship between contemporary governmentality and certain ongoing educational imperatives from different social fields.

\section{Key words}

Educability, educationalization, governamentality, Michel Foucault

Fecha de recepción: Septiembre 26 de 2015 Fecha de aprobación: Noviembre 20 de 2015 
0 presente texto parte do pressuposto de que as múltiplas e incessantes investidas pedagógicas em curso na atualidade, sobretudo aquelas de natureza não formal, passaram a operar não apenas como o braço forte dos processos de ordenamento populacional, mas também como um de seus modi operandi nucleares.

Materializada em termos de uma demanda de formação tão difusa quanto vitalícia, a educabilidade dos cidadãos, tida ora como requisito para o usufruto civil das conquistas democráticas, ora como salvo-conduto individual em um tipo de mundo tido como instável, concorrencial etc., estaria se convertendo em um nexo instituinte da existência social corrente.

Segundo os imperativos categóricos da sociedade pedagógica descrita por Jacky Beillerot (1985), da sociedade totalmente pedagogizada proposta por Basil Bernstein (2003), das políticas da aprendizagem ao longo da vida discutidas por Stephen Ball (2013), ou ainda no que tange aos processos típicos da sociedade educativa esquadrinhados por Carlos Ernesto Noguera-Ramírez (2011), o aprender converte-se numa atividade interminável e onipresente, ao sustentar a emergência de um personagem social heterodoxo: o homo pedagogicus (Deacon \& Parker, 1998).

A irrupção de tal personagem consiste em um fato inédito na história, mediante um mundo em que a circulação de informações sem validação e/ou controle tornou-se a moeda forte das trocas sociais, segundo Michel Serres (2000, p. 133):

0 que é importante, hoje, é que a informação se tornou decisiva para quase todos os métiers [...]. E isto é perfeitamente novo. Por quê? Porque se pode buscar informações em novas fontes, que fazem com que, de forma paradoxal, os novos saibam mais que os antigos. É isso que eu chamo de sociedade pedagógica. Por outro lado, tudo que é televisão, rádio, informação em geral, está estruturado ao modo da distribuição escolar. E mesmo a distribuição escolar no sentido mais tradicional.

Admite-se, portanto, que a aquisição contínua de informações/saberes, sustentada por expedientes de feições escolarizantes, desponta como um princípio incondicionado da organização dos modos de vida na atualidade, ou seja, "como um fenômeno de toda a sociedade, um processo não centrado na escolarização dos cidadãos, mas na civilização das sociedades; não 'escola e sociedade', mas a 'sociedade como uma escola"', na concepção de Roger Deacon e Ben Parker (1998, p. 142).
Encarada dessa maneira, a educação contemporânea não estaria provando nenhuma espécie de indício de insolvência, corrupção ou degeneração. Ao contrário, estaríamos diante do apogeu educativo moderno, agora materializado por uma variedade de práticas ao recobrir todo o tecido social, às quais estaria reservada, como se costuma apregoar, uma resolutividade decididamente maior do que as intervenções escolares tradicionais.

Trata-se, então, de reconhecer, na irredutibilidade da demanda educacional corrente, a sagração - claudicante, no caso escolar, ou florescente, no caso das práticas não formais- do sonho moderno de ordenamento produtivo do mundo das coisas e dos homens. Uma verdade triunfante; um refrão sem contestação de nenhuma ordem; um aspirante sequioso à absolutização histórica.

A eleição de tal perspectiva argumentativa repousa no fato de que, na atualidade, a educação consistiria menos em um bem ou serviço crucial para a alegada edificação da cidadania democrática, e mais em uma eficiente racionalidade de governo de si e dos outros - ou, mais especificamente, um foco de experiência, na acepção foucaultiana, em torno do qual se articulam, "primeiro, as formas de um saber possível; segundo, as matrizes normativas de comportamento para os indivíduos; e enfim os modos de existência virtuais para sujeitos possíveis" (Foucault, 2010, p. 4).

A fim de subsidiar tal argumentação, o texto apresenta os resultados de um conjunto de 12 investigações que vêm sendo conduzidas por um grupo de trabalho sob nossa orientação nos últimos anos, junto à Faculdade de Educação da Universidade de São Paulo, voltado aos estudos foucaultianos na educação. Trata-se de esforços em torno da análise da inter-relação entre a governamentalidade contemporânea (Foucault, 2004; 2008a; 2008b; 2010) e determinados imperativos pedagógicos, em curso em diferentes domínios sociais. Mais especificamente, objetiva-se estimar os deslocamentos de algumas práticas - que, historicamente, não se confundiam com o âmbito pedagógico - como modalidades de condução das condutas de caráter marcadamente instrucional, a balizar as relações que os protagonistas de tais práticas estabelecem com os cidadãos e, no limite, que estes estabelecem entre si.

Visa-se, assim, a atentar para o acento educacionalizante (Smeyers; Depaepe, 2008) de certas esferas da ação humana, doravante amalgamadas em um extensivo projeto sociopolítico de edificação de algo como uma sociedade-escola. 


\section{Para além das fronteiras escolares}

Os dois primeiros trabalhos selecionados referem-se a iniciativas de esquadrinhamento analítico dos processos de educacionalização correntes em diferentes esferas. No primeiro caso, a investigação conduzida por Elisa Vieira, intitulada Sobre o expansionismo pedagógico contemporâneo: uma arqueogenealogia da intensificação das experiências educativas não escolares, parte da hipótese de que experiências educativas não escolares estariam adquirindo uma centralidade cada vez mais proeminente no interior do campo educacional. Assim formulada, tal conjectura dá lugar ao que, no estudo, foi denominado expansionismo pedagógico: movimento caracterizado por enredar as relações entre os homens e as experiências cotidianas como objetos passíveis de conhecimento e intervenção de cunho pedagógico.

Sustentada pela teorização foucaultiana, a empreitada investigativa considera a educação como uma das instâncias intrinsecamente envolvidas na produção de certos modos de subjetivação contemporâneos, tendo em mente o fato de que as práticas de teor educacionalizante vêm sendo apropriadas como uma estratégia social onipresente, temporal e espacialmente, de conformação da experiência humana.

De que modo se produziu uma sociedade plenamente educável? Como chegamos a pensar o que hoje pensamos de modo consensual? Que matrizes de pensamento forneceram as bases a partir das quais aquilo que hoje somos tornou-se possível?

A fim de esboçar algum tipo de réplica a tais questões, foi eleita a produção acadêmico-científica brasileira ao longo das últimas décadas, tomada como um escopo suficientemente sólido e abrangente para testemunhar aquilo que se pensou e se operou no campo educacional. Mais especificamente, foram selecionados 20 periódicos da área pedagógica, cuja análise deu-se em duas frentes: numa delas, os números dos periódicos publicados nos últimos 20 anos foram tratados em conjunto; na outra, a Revista Brasileira de Estudos Pedagógicos - o periódico mais longevo no país, em circulação desde 1944- foi objeto de uma análise mais detida, considerando-se toda a sua extensão.

Por um lado, a intenção aí foi flagrar determinado momento em que a problemática da educação não escolar irrompia no bojo de discussões para as quais ela ainda não era resposta predominante, embora ali estivesse em germe. Tratou-se de buscar sua emergência em uma discursividade dispersa, na qual, decerto, conviviam outras possibilidades enunciativas. De outro lado, o intento foi abordar as fronteiras do campo pedagógico configuradas em tal arquivo, de modo a compreender sua expansão nos termos de uma objetivação performativa de novos domínios de atuação. Buscou-se, enfim, compor um inventário dos saberes, das práticas e dos modos de intervenção que têm sido mobilizados na experiência educativa não escolar.

De modo geral, a expansão do intento pedagógico para além dos limites escolares afirma-se como um movimento crescente nas duas últimas décadas; sua manifestação desponta em produções tanto nacionais, quanto internacionais; a maior parte dos trabalhos manifesta-se, de algum modo, favorável a iniciativas educacionais não formais; o alcance de aplicação de tais práticas abrange ao menos duas dezenas de regiões temáticas distintas e paralelas, as quais perfazem quatro grandes eixos de dispersão do intento educacionalizante - na extensão dos tempos da vida; na extensão dos espaços cotidianos; na extensão das questões socioculturais; na extensão das preocupações com a formação, incluindo os contornos próprios da atuação do campo pedagógico não escolar.

Um dos principais saldos analíticos da pesquisa remete ao reconhecimento da existência de uma maquinaria educacional espraiada pelo espaço social, da qual a escola é certamente parte, mas não a única. Isso porque, se cidadão e aluno, em alguma instância, passaram a ser condições subjetivas complementares dos indivíduos contemporâneos, não parece ser exclusivamente na instituição escolar que essa associação vem sendo exercitada. Seria plausível admitir, portanto, que estamos a testemunhar uma acentuada proliferação das práticas educativas e um concomitante fortalecimento dos modos pedagogizantes de modulação da experiência social, dando margem a uma espécie de alunização radical dos cidadãos contemporâneos.

Em um diapasão semelhante ao da pesquisa de Vieira, outra investigação, agora focada na governamentalização dos espaços urbanos, foi levada a cabo por Ana Paula Nunes Chaves. Intitulado Por outras espacialidades: uma cartografia da pedagogização no Parque Ibirapuera, SP, o trabalho teve como propósito principal perspectivar analiticamente como os processos de pedagogização forjam e governam determinados espaços e espacialidades. Para tanto, partiu-se do pressuposto de que as práticas sociais são moduladas por jogos de força que as criam e recriam espacialmente, sobretudo por meio de mecanismos pedagogizantes que se alastram cada vez mais no cenário urbano contemporâneo. 0 espraiamento 
de uma educabilidade constante, ininterrupta, que se dá a qualquer momento e em diferentes esferas do espaço social nas cidades, conforma processos de pedagogização que não deixam de criar, governar e gerir espacialidades.

Por meio de uma análise mais apurada das relações espaciais, pode-se atestar não somente como o espaço que está organizado, mas também como se articulam interesses e disputas de diferentes ordens. Desse modo, apreender os processos de produção e organização espaciais, auxilia a deslindar o complexo jogo por meio do qual se produz coletiva e subjetivamente o mundo que não apenas nos rodeia, mas que também nos compreende. Isso implica compreender como as relações sociais produzem, controlam e constroem espaços habitados por sujeitos não apenas constrangidos pelas formas espaciais, mas também ativos e inventivos, que as transformam e recriam.

Assim, a pesquisa debruçou-se sobre a relação entre educação e governo de espaços/espacialidades nas práticas instituídas no Parque Ibirapuera, em São Paulo, dada sua importância capital na fisionomia urbana da cidade. Nele, o provimento de museus e vários outros espaços culturais, além de parque infantil, ciclofaixa, escola de jardinagem, escola de astrofísica, áreas para prática de esporte, planetário etc. revela espacialidades cotidianas atravessadas por um conjunto de mecanismos pedagogizantes.

A cartografia realizada pleiteou-se uma derivação da perspectiva arqueogenealógica foucaultiana, operando segundo duas frentes de trabalho complementares: em primeiro lugar, a análise de documentos oficiais acerca do Parque que instituíram as prerrogativas para sua criação, em 1954, até seu funcionamento atual; de modo complementar, outra frente arquivística foi composta pelos discursos jornalísticos veiculados a seu respeito em diferentes décadas, de 1954 a 2014. Em segundo lugar, realizaram-se a observação e o registro de práticas ali em voga.

Os resultados evidenciaram uma racionalidade vincada em práticas de pedagogização, estas aliadas a tecnologias específicas de governamento dos espaços. Trata-se de um cenário sociocultural que apresenta lógicas de governo heterogêneas, as quais coexistem através do tempo, ajustando-se, desajustando-se e alterando-se.

No arco temporal das seis décadas analisadas na investigação, pôde-se conferir, de um lado, o câmbio das tecnologias de governo que configuraram o Parque como um espaço aberto, móvel e flexível, privilegiando a atuação de mecanismos pedagogizantes de diferentes naturezas. De outro lado, deparou-se com distintas formas de uso e de apropriação que entrecruzavam as malhas do instituído, dando visibilidade a novos atores, a fenômenos sociais e a espacialidades outras, bem como a desvios e a contracondutas que suscitavam traços discretos e fugidios de uma heterotopia urbana.

\section{O jornalismo em questão}

Outras duas pesquisas, não obstante, apartadas no que se refere ao escopo temporal aludido, tomam o viés governamentalizador das práticas jornalísticas como objeto de análise.

A primeira delas - Um terremoto, uma biblioteca, um jornal: a emergência de uma nova ordem social pelos impressos luso-brasileiros nos séculos XVIII $e$ $X I X$, sob a responsabilidade de Gisela Maria do Valvolta-se à Lisboa pós-terremoto, em 1755 , e à criação do primeiro jornal impresso no Brasil, a Gazeta do Rio de Janeiro, após a instalação da Coroa portuguesa no Rio de Janeiro, em 1808. Seu recorte temático situa-se na relação entre jornalismo e educação, entendendo aquele como uma atividade que veicula, por meio da produção sistemática de notícias, vetores enunciativos responsáveis por um extenso e intricado processo de pedagogização social.

0 enfoque teórico do trabalho parte da premissa da prática jornalística como governo dos homens, enveredando por sua forma de funcionamento em tempos e espaços longínquos, pelas emergências que ali despontaram e que ainda reverberam no presente. Segundo os dados analisados, os jornais tornaram-se uma ferramenta coprodutora de uma dada grelha explicativa da vida. No gesto jornalístico de narrar, opinar e informar, perfaz-se certa inteligibilidade acerca do presente, conectando-o ao passado.

Trata-se de um dos meios privilegiados da arte de governar que, no caso da pesquisa, inicia-se no que parece constituir a emergência de uma gestão das formas de vida, por meio da (re)construção das condições de vida de uma população e de um entorno social gerenciável, seja pela recuperação de uma cidade devastada (Lisboa), seja pela invenção de uma Corte nos trópicos (Rio de Janeiro). As convocações tanto aos sobreviventes de um dos mais catastróficos terremotos europeus, como aos moradores de uma quase vila colonial elevada à condição de Corte de um império, despontam como um manancial de enunciados baseados na produção de uma memória, de uma nacionalidade e do emaranhamento entre súdito e cidadão, os quais passam a constituir o quadro de referências de um novo projeto sociopolítico. 
A emergência da entrada da vida e de seus mecanismos próprios no domínio das letras normativas impressas nas páginas dos jornais, remete, segundo a pesquisa, a uma rede capilar de gestão política operando por uma economia gestionária da população que alimentou as engrenagens de funcionamento de tecnologias criadas para servir a um processo constante e hiperdisseminado de aperfeiçoamento da vida. Assim, pôde-se dimensionar os traços fundadores de um movimento que estabeleceu uma nova maneira de governar, a qual estabeleceu laços de comunicação e educação diuturna pelas letras dos jornais.

De modo análogo, Guilherme Magalhães Vale de Souza Oliveira debruçou-se sobre uma revista cultural contemporânea com vistas a entabular uma interpelação das relações entre filosofia e mídia. A pesquisa intitulada Da popularização da filosofia à expertise filosófica: uma problematização do papel do intelectual na mídia (Revista Cult 1997-2013) focalizou o espraiamento e a variação das artes de direção de consciência, perpetradas por filósofos por intermédio da mídia contemporânea, problematizando-as não em termos de ideologia ou manipulação, verdade ou falsidade das investidas de partidários de um autor ou ideia, mas como configuração agonística de diferentes vertentes do pensamento nos perenes jogos de subjetivação.

Do ponto de vista investigativo, realizou-se um mapeamento de enunciados de diferentes naturezas que se dedicaram a pensar os rumos da popularização da filosofia e a difundir produções culturais alegadamente filosóficas. Em seguida, tendo a Revista Cult como plataforma empírica de investigação, mapearam-se os artigos e entrevistas realizados por e com filósofos - ou intelectuais com alguma formação em filosofia- num período de 17 anos, de 1997, ano de fundação da revista, até 2013, totalizando 186 fascículos.

Em consonância com os estudos de Michel Foucault sobre a Modernidade e os jogos de governo de si e dos outros, considerou-se a popularização da filosofia como parte de um movimento tardio de racionalização e pragmatização do pensamento, com o fito de conformar modos de vida a conhecimentos e valores morais cientificamente fundamentados.

O filósofo na mídia passa, então, a aliar-se a práticas corretivas e terapêuticas, exercendo a função de pastor de uma suposta boa consciência, na esteira da qual cidadania, democracia e formação continuada convertem-se em diretivas morais. Nos jogos contemporâneos de governo de si e dos outros, o filósofo, em sua versão popularizada, desponta como um especialista que deve incitar o sujeito a se adequar aos preceitos vigentes. Ao fazê-lo, converter-se-ia, parafraseando Foucault, em um mero funcionário da verdade.

Segundo a mirada da investigação, os filósofos da Cult deixam de se atribuir o papel de especialista da história da filosofia ou de um filósofo específico, em favor do exercício de narrativas ora aconselhadoras, ora denunciadoras. Assim, detectou-se a conversão da prática filosófica — quando aliada à mídia- em mais uma expertise da conduta humana, por meio de sua evocação de práticas de cunho estético e psicopedagógico. Tal prática findaria por participar do amplo rol das estratégias de governo de si e dos outros em circulação atualmente.

\section{As práticas artísticas como objeto analítico}

Outra vertente das pesquisas realizadas diz respeito à análise de determinadas práticas artístico-culturais e seus aportes educacionalizantes. Iniciemos com a literatura.

Sob o título Voz e silêncio da escrita: cem anos de depoimentos de literatos brasileiros, a pesquisa conduzida por Silas Sampaio Garcia devotou-se à produção, circulação e à apropriação de depoimentos de diferentes gerações de escritores brasileiros, por meio da análise de entrevistas constantes de 36 publicações que circularam no Brasil no decorrer de um século - de 1905, data dos primeiros inquéritos literários no país, a 2004.

Num primeiro momento, interrogou-se o fascínio tradicionalmente exercido pela vida dos escritores. 0 intuito foi perspectivar, no surgimento da prática de entrevistá-los, a emergência de uma nova frente discursiva, nomeada voz pública do escritor, e fruto do encontro entre práticas jornalísticas e literárias no início do século $\mathrm{XX}$.

A emergência dessa nova frente é entendida como a atribuição ao escritor de um papel educativo perante as massas, o qual se cumpre menos como modalidade de uma prática diretiva explícita, e mais por meio da produção e circulação de enunciados de estatuto confessional implicados na oferta de modelos de vida, de leitura e de escrita. Estatuto, ademais, que confere ao discurso aí em voga um teor de verdade inquebrantável, na medida em que oriundo de uma suposta essência subjetiva de quem o profere.

Assim, ao ganhar voz e corpo nas páginas de jornais, rádios, televisões e tendas de feiras literárias, o escritor estaria cumprindo seu papel governamen- 
talizador em uma sociedade obstinada em lançar luz sobre determinados problemas, tais como a vida e o ofício literários, e espargir o conhecimento acerca deles sob a alegação de esclarecimento e, em última instância, formação dos indivíduos. Desse modo, gestos e experiências como a escrita e a leitura são precedidos por um saber sobre eles - um saber difuso, mas não por isso menos eficiente.

$\mathrm{Na}$ intenção de dar a ver as linhas de força postas em ação nesses 100 anos de depoimentos literários no Brasil, o trabalho inspirou-se no procedimento arqueogenealógico de Michel Foucault, buscando traçar os deslocamentos de práticas, bem como de problematizações que emergiram na superfície dos depoimentos.

Tendo em mente o interesse crescente por aquilo que os escritores teriam a ensinar ao homem comum, os depoimentos analisados despontam como uma maquinaria produtiva de enunciados que se espraiam pelo entorno social, versando sobre modos artísticos tanto de vida quanto de escrita, sendo estes últimos supostamente originários de alguma instância criadora inerente ao sujeito literato. Novamente com Michel Foucault, divisa-se em tal discursividade um acirrado mecanismo de governo da prática escritural, sobretudo por meio da afirmação recorrente de uma dita natureza criadora atrelada aos literatos.

Outra investigação sobre o campo literário foi conduzida por Flavio Tito Cundari da Rocha Santos. Intitulado Escrever, verbo intransitivo: ascensão e ocaso de uma mestria epistolar entre literatos brasileiros, o trabalho define-se como uma análise das relações de governo estabelecidas por meio e em torno da escrita literária, as quais se vêm afirmando no Brasil desde o final do século XIX. Dita análise toma como ponto de partida alguns discursos contemporâneos sobre o âmbito privado das vidas dos literatos, com o intuito de questionar a proverbialidade com que se enaltecem tanto os textos taxados de literários, quanto as vidas de seus responsáveis. Conforme a discursividade em questão, haveria autores dos mais variados tipos, mas todos eles portariam uma identidade comum: a de escritor. Esta, para além de seus caracteres distintivos, teria assumido ao longo da Modernidade uma definição em que se vinculam certo exotismo e um modo de vida de diuturna diferenciação em relação aos demais.

Em meio a esse quadro geral, foram selecionadas as correspondências trocadas por jovens literatos e escritores reverenciados, intituladas cartas de formação. Tais documentos, tendo dado origem a diversos estudos literários, são usualmente descritos como suporte de certo tipo de mestria, em que se versa não exclusivamente sobre a produção escrita dos autores, mas também sobre as escolhas pessoais dos destinatários, sobre o modo como estes se relacionavam consigo próprios e sobre as experiências pelas quais deveriam passar.

As apropriações do arquivo epistolar de literatos, visto suscitarem o predicado de uma implicação entre a vida dos literatos e a das demais pessoas, converteram esse tipo de empiria e a formação por ela operada nos objetos centrais da investigação. Para tanto, analisou-se um conjunto de 1444 cartas trocadas entre 42 aspirantes a escritor e Machado de Assis, bem como Mário de Andrade, sendo a escolha desses dois literatos justificada por ambos terem acumulado, ao longo dos anos, um grande séquito de jovens que os admiravam e que buscaram se valer de sua orientação por meio das missivas.

0 trabalho investigativo viu-se delimitado por um horizonte teórico-metodológico claro: o gesto arqueogenealógico descrito por Foucault, o qual visa a manter sob suspeita os regimes de veridicção em que se engendram afirmações peremptórias sobre a vida, como se se tratasse de matéria essencialista e, portanto, inequívoca. Em conformidade com tal premissa, o objetivo da investigação foi o de demonstrar que a literatura que ora nos soa como a escrita verdadeira, e necessária a uma existência completa portaria um passado incapaz de fundamentá-la como tal.

Por meio da análise das cartas, foi dada a ver menos uma prática educativa própria do fazer literário, e mais o engendramento de modos diferentes de se conceberem a escrita e a formação dos escritores. Ao fim e ao cabo, deparou-se com uma micro-história de tais modos, permitindo atestar a emergência e o declínio de uma mestria ético-epistolar. Seu ápice teria ocorrido nas correspondências de Mário de Andrade, as quais estabeleciam uma relação de inegável potencial transformador das existências de seus destinatários, instando-os contra os ditames da instituição literária. Tal experiência, entretanto, ocorrendo no interior da própria instituição, só se pôde realizar a custo de uma relação dúbia com a prática da escrita.

Outra prática artístico-cultural de destaque, o teatro, é objeto de duas investigações. Sob o título Intoleráveis e cativos: o lugar do espectador nas práticas teatrais brasileiras (1855-1958), a pesquisa de Luiz Paulo Pimentel de Souza tem analisado as emergências, as rupturas e os deslocamentos da discursividade sobre as práticas teatrais no Brasil, estas justificadas socialmente segundo suas ambições educativas. 
Partindo da evidência de que, nas últimas três décadas brasileiras, vem se intensificando a presença de movimentos sociais compostos por artistas, os quais pleiteiam a criação e a manutenção de políticas públicas para o teatro, o estudo pondera que a atribuição de um valor essencialmente positivo às práticas teatrais pode cercá-las de um sentido transcendente, incorrendo em um enquadramento tão somente moralista. Aqui, faz-se necessário um cruzamento teórico-metodológico da relação arte-poder, a partir de estudos realizados por Foucault.

Entende-se que a aliança investigativa com alguns procedimentos de análise e teorizações foucaultianas pode possibilitar uma tomada de distância das leituras recorrentes que reputam as práticas artísticas e teatrais, como sempre estando situadas do lado de fora das relações de poder, ou seja, como resistência.

Interessa à pesquisa, portanto, investigar as associações entre as práticas teatrais e a educação, na perspectiva do governo dos homens, ao longo de determinado período da história do teatro brasileiro (1855-1958), por meio da problematização das formas pelas quais foi-se edificando ao redor da discursividade teatral um saber acerca do próprio âmbito artístico, criando espaços de distinção e tensão entre formas de fazer mais verdadeiras que outras. Intenciona-se, ainda, arrolar formas pelas quais o teatro, entendido como instituição, participou da constituição de determinados jogos de subjetivação, formalizando as fronteiras tanto para uma vida artística quanto para uma vida não artística.

A empiria da pesquisa consiste em um arquivo que reúne a fortuna crítica de 17 autores que escreveram sobre o teatro de 1855 (inauguração do Teatro Ginásio Dramático) a 1958 (estreia da peça Eles não usam Black-Tie). 0 arco temporal da pesquisa abarca a época de precariedade absoluta da situação teatral no país, seus debates, suas proposições e transformações, até o final do movimento do teatro brasileiro moderno, que instituiu as bases de uma experiência teatral da qual os brasileiros hoje são herdeiros, de alguma forma.

Ademais, a crítica teatral é aqui pensada como documento histórico não apenas de memória, registro ou opinião, mas como uma prática produtora de sentidos, responsável por introduzir ativamente as práticas teatrais no jogo do verdadeiro e do falso, constituindo o teatro como objeto de pensamento.

Outra investigação em curso, agora a cargo de Sidmar Silveira Gomes, é aquela intitulada Teatro infantil brasileiro: uma história outra. A discussão levada a cabo no estudo ancora-se em cinco temas recorrentes no debate sobre o teatro infantil: 1) o protótipo de infância veiculado nos discursos pronunciados pelo adulto sobre a criança no interior das práticas do teatro infantil; 2) as relações de codependência entre teatro infantil e educação; 3 ) os discursos éticos e estéticos inerentes ao teatro infantil operando em razão do espectador adulto que acompanha a criança e que escolhe ao que ela irá assistir; 4) as escolhas temáticas e estéticas feitas pelo artista adulto a partir de seu projeto de infância; e 5) de um lado, os discursos que engendram o tema das faixas etárias e das demarcações pautadas em fases de desenvolvimento da criança; de outro lado, o teatro sem fronteiras etárias.

A partir de tais categorias analíticas, visa-se à construção de uma mirada histórico-filosófica sobre a constituição do teatro infantil brasileiro, tendo como inspiração teórico-metodológica a arqueogenealogia de Foucault, no que se refere aos deslocamentos, às emergências e contingências das práticas do teatro infantil brasileiro, com o fito de analisar como, ao longo de sua história e a título de difusão cultural, elas afiliam-se ao rol das experiências educativas não escolares e de uma espécie de pedagogização generalizada da sociedade.

O último estudo enquadrado na subcategoria das práticas artísticas é aquele sob a responsabilidade de Adriana Pedrassa Prates: Arte e governamentalidade: uma análise de práticas expositivo-educativas nos discursos de críticos, curadores e artistas (Brasil, 1911-1984).

0 objeto da pesquisa refere-se aos recentes modos pelos quais as instituições culturais têm efetivado, no campo da arte, suas práticas expositivo-educativas -no que concerne tanto às megaexposições que pululam nos circuitos internacionais, quanto às novas configurações que as constituem na interface com o que se designa como ecomuseus, museus comunitários, de sociedade, de território, etc.-, responsáveis por uma crescente e massiva visitação pública a tais espaços.

Tendo em vista a acontecimentalização do dispositivo arte-museu-educação, o arco temporal da pesquisa tem seu marco inicial em 1911, momento em que o primeiro museu de arte do Brasil - a Pinacoteca do Estado (1905) — é franqueado à visitação pública com a Primeira Exposição Brasileira de Belas Artes. 0 marco final da pesquisa é 1984, com a exposição Como vai você, Geração 80? - momento em que, internacionalmente, a construção de museus artísticos vive um boom e passa a ser fortemente acompanhada pela presença da iniciativa privada, apresentando elementos de uma experiência formativa em arte para as populações. Entre tais mar- 
cos, uma série de exposições são focalizadas como elementos constituintes do arquivo empírico da pesquisa, de modo que, sob o crivo arqueogenealógico foucaultiano, possam funcionar para que uma história outra da arte seja formulada.

Trata-se de analisar, portanto, as alianças históricas que se deram (e que continuam a operar) entre as práticas discursivas centrais da arte no Ocidente e as práticas expositivo-educativas realizadas em espaços culturais consagrados desde sempre ao processo civilizatório moderno. Ao investigar a emergência e a proveniência da arte como governo dos homens, na reciprocidade de sua relação com o processo próprio da pedagogização museológica, visa-se, a partir do diálogo com a perspectiva arqueogenealógica foucaultiana, a evidenciar a eficácia de uma investida educativa cujas palavras de ordem parecem desaparecer na ilusão de uma lógica inclusiva e culturalmente edificante, em favor da disseminação de um governamento de feições biopolitizantes.

\section{Modulações do discurso pedagógico}

Também se valendo de procedimentos analíticos de base arqueogenealógica, os três últimos trabalhos trazem à tona as diferentes modulações, segundo seus aportes históricos e filosóficos, anteriores e posteriores à modernidade educacional.

Sob o título Carne recortada, almas expostas: da visualização escolanovista à utopia do homem aprimorável, a pesquisa de Marcelo Rito enveredou inicialmente pelos debates acadêmicos que se devotam ao encontro entre saúde e educação para que fosse possível problematizar a emergência da escola moderna no Brasil, instituída por práticas higienistas presentes já no início do século XX.

0 momento escolanovista foi eleito como lócus privilegiado para situar a escolarização moderna como campo de intercâmbio de saberes e normas, cuja consecução implicou existências imersas na forja de si como objeto científico. Ou seja, considerou-se que, por meio de ações como exercícios planejados, tabulações de resultados, autoinspeção íntima, instigação à liberdade etc., o aluno escolanovista tornou-se produtor de uma narrativa de si que fez de sua intimidade o cerne da longa história das objetivações, normalizações e terapêuticas psicobiológicas.

Ademais, foi possível aperceber-se da presença de outro elemento considerado de fundamental importância: a possível constituição, no contexto de implantação do escolanovismo, das condições históricas para o despontar da atual concepção cerebralista de ser humano. Segundo tal noção em voga nos atuais discursos da neurociência, o cérebro teria tomado o lugar das pregressas concepções de alma e de mente para referenciar aquilo que hoje se denominaria indivíduo. Desse modo, fenômenos subjetivos, cognição, conduta e liberdade seriam recodificados como ações pessoais compreensíveis a partir de processos visualizáveis em termos de moléculas, neurônios, sinapses etc.

Sustenta-se, nesse sentido, a hipótese de que a conquista contemporânea do corpo pelos discursos cerebralistas não teria alcançado proeminência, caso não tivessem os psicopedagogos escolanovistas formulado leis que atrelavam os processos cognitivos a ações previsíveis e transformáveis, segundo critérios estabelecidos na progressiva transformação do corpo humano em objeto da previdência higiênica.

Considerando a imanência do higienismo nas práticas escolares modernas, foram perscrutados dois momentos da história educacional brasileira, distantes entre si 80 anos: as décadas de 1920-1940 e as de 1990-2010. No primeiro caso, analisou-se a Biblioteca de Educação, coleção de livros publicados entre 1927 e 1941 sob a editoria de Lourenço Filho, reconhecido pensador escolanovista; no segundo caso, foram apreciados 56 artigos publicados em periódicos educacionais entre 1993 e 2013, cujas temáticas estiveram ligadas ao escopo da Escola Nova.

De modo complementar a ambos os conjuntos de dados, foram focalizadas as teorizações que se criaram quando se produziram suposições acerca do funcionamento da anatomia corporal. Tais teorizações foram compiladas em dois campos afastados um do outro por mais de 100 anos: a medicina anatômica brasileira e a biomedicina contemporânea. No primeiro caso, trata-se de preleções emitidas, entre 1841 e 1863, por médicos vinculados à Academia Imperial de Medicina; já no caso da biociência, o campo de investigação foi constituído por uma coletânea de enunciados abrigados no campo da biomedicina contemporânea. A partir dessas duas práticas discursivas, vislumbrou-se que ambas teriam produzido focalizações que anexaram os olhares dos experts aos corpos manipulados, determinando suposições de funcionamento no momento mesmo em que interferiam neles, fosse para curá-los ou modificá-los.

Apoiada em tal instrumental empírico, a pesquisa problematizou possíveis proveniências do acoplamento de práticas anatômicas e psicopedagógicas à emergência de uma utopia do homem aprimorável. A busca por uma corporeidade visualizada em termos de seu desenvolvimento progressivo, desde 
os tempos que remontam à medicina do século XIX, teria alimentado toda sorte de intervenções, tanto no ambiente social-urbano quanto no espaço entalhado pelas individualidades.

Concluiu-se, assim, que o processo de subjetivação que resultou na atual utopia do homem aprimorável somente poderia ter sido constituído se, eventualmente, os sujeitos incorporassem a crença de que são seres incompletos e vulneráveis, à espera de aconselhamentos dos personagens responsáveis por manter operante a concepção de vida que está atrelada a dita utopia.

Outro estudo, agora tendo como alvo os discursos fundadores da pedagogia científica, foi conduzido por Claudia Ribeiro Calixto: Querer, obedecer e empreender: o governo de si e dos outros nos discursos pedagógicos (final do século XVIII e início do XIX).

Tendo como horizonte teórico-metodológico o gesto investigativo de Michel Foucault, sobretudo por meio de conceitos operadores como poder pastoral e governamentalidade, a investigação teve como ponto de partida as proposições correntes acerca do empreendedorismo, em torno do qual gravitam noções como felicidade, sucesso, destino, eficiência e produtividade. Tal formação discursiva dispõe ao indivíduo uma convocação a uma dada forma de autogoverno, baseada em termos de gerenciamento da própria vida, o qual deve ser flexível, adaptável, dinâmico, inventivo, eficiente e responsável.

Com vistas à elaboração de uma visada arqueogenealógica da constituição da noção de homem empreendedor como subjetividade aprendente e autogovernável, procedeu-se a uma análise dos textos de Pestalozzi, Froebel e Herbart, bem como da obra pedagógica de Goethe, Os anos de aprendizado de Wilhelm Meister.

Os textos dos três pedagogos operam em torno das noções de verdade e salvação. Valendo-se da educação, o homem deveria ser dotado da capacidade de conduzir a si mesmo por meio de sua liberdade. A capacidade de ser educável seria condição imanente e acionada a partir de determinação própria, liberdade e consciência. Ainda, a educação constituiria uma forma de ação que possibilitaria a cada um fazer-se a si mesmo, forjando uma obra de si por si. 0 objetivo magno da educação seria a descoberta da vocação da própria vida, o que incluiria um conhecimento íntimo da personalidade do sujeito, de sua verdadeira natureza. Em suma, as energias do homem constituiriam a matéria ética da pedagogia científica.
O homem investido por Goethe, tal como em Froebel, Pestalozzi e Herbart, é um ser em desenvolvimento, reflexivo, que aprende com as lições da natureza e com a experiência. É possível, assim, identificar aí certa modulação do poder pastoral. A salvação há de ser conquistada principalmente pelo indivíduo, que não mais dependerá exclusivamente do pastor. Este é inoculado no sujeito, caracterizando aquilo que entendemos ser a emergência da função-educador na Modernidade, a definir uma relação de matriz pedagógica do indivíduo consigo mesmo.

A leitura dos textos dos referidos autores, bem como uma investigação de suas biografias remeteu a mais outra paragem analítica: o pietismo, formação discursiva que compôs a ambiência ético-política daqueles personagens históricos.

Tal como outros movimentos da época, o pietismo trouxe à baila questões problemáticas para o governo da população, de forma a equacionar o governo de si ao governo dos outros, efetivando uma espécie de ascese intramundana, segundo a qual o indivíduo, por meio de uma prática cristã devotada ao labor incessante, equipar-se-ia como sujeito predestinado a usufruir a bem-aventurança divina na terra.

Pelo trabalho analítico das fontes selecionadas, pôde-se observar um deslocamento do governamento teístico para uma noção de salvação laica ancorada na ideia do homem educado como operador de seu destino. Observou-se a construção da noção de um sujeito capaz de gerir sua vida, imaginando-se construtor de sua própria história, por meio de determinadas práticas pedagógicas sobre si mesmo, tais como: voltar o olhar para si, buscando sua motivação e sua verdade supostamente interiores; descobrir e desenvolver seus talentos; aprender a aprender, retirando das experiências com o mundo lições para uma vida bem-sucedida; identificar e aprimorar suas habilidades e aptidões, mantendo-se atualizado; cuidar da própria saúde, fazendo-se saudável e produtivo; produzir-se reflexivo e efetuar uma escrita biográfica — já com margens e signos impressos e imprimíveis nos processos de veridiç̧ão em operação na contemporaneidade.

Uma abordagem próxima à de Calixto encontra-se na pesquisa $O$ pastorado cristão e o dispositivo pedagógico: elementos para uma arqueogenealogia da educação escolar, de Carlos Rubens de Souza Costa. Nela, buscou-se saber se o pastorado cristão relacionou-se, de alguma forma, com a problematização da educação escolar no período de sua maior influência, do século VI ao século XVII. Para tanto, foram escolhidos três 
momentos históricos específicos: o do aparecimento da Regra de São Bento, o da reforma luterana e o do da Didática Magna de Comenius.

Em diálogo com as formulações foucaultianas, as hipóteses principais do trabalho foram de que não existiria uma forma única de pastorado cristão e de que diferentes tipos de pastorado engendrariam diferentes formas de problematização da educação. Trabalhou-se, assim, com a ideia de três pastorados: o cenobítico, o luterano e o pedagógico.

Um ponto de convergência entre eles reside na finalidade atribuída à educação: conduzir o educando à salvação eterna. Outro ponto refere-se à queda ou ao pecado. Nos três casos, a educação teria a ver com o fato de que o homem, ao pecar, desviou-se de Deus, devendo a ele retornar. Mas é a partir daí que as divergências começam a pedir passagem, uma vez que há muitas diferenças no modo como foram problematizados tais queda e retorno.

Ao considerar a queda, São Bento focalizou aquilo que teria sido sua essência e sua motivação. Concluiu que a essência do pecado de Adão e de todos os pecados do homem era a desobediência e que sua motivação era a soberba, o orgulho do homem. A partir desse diagnóstico, imaginou que o pecado podia ser evitado por meio de um trabalho ascético (a "ascética da humildade") que visasse a quebrar o orgulho e a desenvolver a capacidade de pronta obediência em quem que o praticasse. Assim, este poderia retornar àquele de quem se afastara ao pecar. Entretanto, é necessário evitar situações que sejam ocasiões para que o pecado irrompa. E o papel da vigilância constante é justamente esse. Por sua vez, o exame de consciência e a confissão visam a surpreender o pecado em seu nascedouro, quando apenas se insinua e ainda não tomou conta da alma. Assim, em torno da prevenção do pecado, o pastorado cenobítico inventou e mobilizou toda uma variedade de meios, que ficaram como que à disposição das mais diferentes instituições. E as escolas católicas do início dos tempos modernos parecem ter sido as maiores herdeiras desses meios.

Ao considerar a queda, Lutero, por sua vez, defendeu a ideia de que a natureza humana teria se tornado totalmente corrompida, mesmo nas suas faculdades mais nobres. Assim, por suas próprias forças, o homem não poderia não pecar. Toda a variedade de meios inventados pelo pastorado cenobítico para prevenir o pecado passa a ser simplesmente inútil. A própria crença de que pode, recorrendo a essas artimanhas, evitar o pecado seria uma soberba que precisaria ser quebrada. A salvação do homem passaria por uma humilhação produzida não pela ascética da humildade, mas por aquela produzida pela lei. A revolta pastoral de Lutero operou uma verdadeira desconstrução das velhas formas de pastorado e engendrou um pastorado enxuto: o ministério da palavra. 0 homem só se salvaria pela fé, e esta vem pelo acesso à Escritura. Esse acesso, por sua vez, demanda que todo cristão seja alfabetizado.

Comenius, por sua vez, considerou que o homem, por mais corrompido que tenha sido pelo pecado, guarda em sua natureza as sementes da ciência, da moral e da piedade, as quais requerem apenas um estímulo e uma sábia orientação para desabrocharem. 0 caminho da regeneração do homem não mais residiria no ostentoso aparato cenobítico criado para a prevenção do pecado, nem no exclusivo recurso luterano à palavra de Deus, mas numa reta educação de crianças e jovens. Movido pela ideia de que é mais fácil e mais eficaz formar o homem na primeira idade, Comenius inventa um pastorado inteiramente singular, porque especializado em conduzir crianças; um pastorado que podemos chamar de pedagógico.

Pode-se ver, assim, que as diferentes formas do pastorado cristão produzem diferentes formas de problematização da educação escolar. No entanto, é possível situar algumas proveniências: o pastorado cenobítico parece ter conferido ao dispositivo escolar a preocupação não só com o conhecimento individualizado dos alunos, mas também com os meios para obtê-lo (a vigilância constante, o exame de consciência, a confissão); o pastorado luterano abriu o caminho para torná-lo público e obrigatório; e o pastorado pedagógico de Comenius oportunizou-lhe a primeira grande sistematização teórica.

\section{Considerações finais ${ }^{1}$}

0 panorama geral das investigações realizadas não deixa dúvidas quanto ao espectro educacionalizante que parece recobrir o cenário sociopolítico, desde seus alvores modernos -incluídas suas proveniências, em alguns casos.

Com efeito, a proliferação de práticas portadoras de intencionalidades alegadamente educativas parece sinalizar um prolongamento não apenas reverberativo, mas hipertrofiado das imagens seculares de emancipação, autonomia e liberdade idealizadas pelos pedagogos iluministas, intrinsecamente atreladas às prospecções de felicidade, completude e bem comum subjacentes aos discursos edificantes

1 As reflexões conclusivas do artigo são uma retomada daquelas
já veiculadas por Aquino (2012). 
que, desde o advento da Modernidade, vêm conferindo ao território educacional lato sensu o selo de fortaleza inexpugnável.

Entretanto, se plausível for a hipótese de que as práticas escolares na contemporaneidade, são atravessadas por nítidos efeitos de disjunção entre o excesso saturante de expectativas a elas atribuídas, e seu pífio alcance do ponto de vista pedagógico stricto sensu, e, além disso, de que é possível atestar uma acirrada propagação de práticas de teor e vocação pedagogizantes, agora não mais apenas escolares, dispersas de modo difuso no tecido social, será igualmente plausível deduzir que a agenda educacional, em suas complexidade e multidimensionalidade, vem angariando um vigor autolegitimador jamais antes visto.

Nesse sentido, a irradiação de práticas alegadamente educacionais estaria a deslindar não uma suposta decadência do projeto escolar moderno, mas um deslocamento do epicentro nervoso da tradição educativa, antes ocupado exclusivamente pela instituição escolar.

Ora, o problema que ressurge sem cessar é o da persistência incólume de um discurso apologético sobre o agir educacional, consubstanciado na ferrenha promessa de salvação dos homens e da história que nos ata uns aos outros, por meio da miragem decretada de um mundo novo, de uma sociedade cultivada, de um futuro prodigioso logo adiante. Bizarrices convencionadas por seu mero valor de uso, admitamos.

Alfredo Veiga-Neto (2004, p. 81) assim sumariza tal expediente:

Se combinarmos salvacionismo com prescritivismo e normativismo, compreenderemos o messianismo do pensamento pedagógico contemporâneo, sempre à espera de uma nova e definitiva teoria, de uma nova ou definitiva fórmula, de um novo ou definitivo método que finalmente deem conta dos males deste mundo cavernoso.

Mediante tal estado de coisas, na esteira do qual vulnerabilidade, voluntarismo e estagnação das ideias pedagógicas se confundem por completo, torna-se inadiável o cultivo de um olhar recalcitrante —seja no âmbito investigativo, seja nas intervenções empíricas- em relação ao que se nos passa quando se trata de educar; um olhar em alerta constante quanto aos múltiplos constrangimentos que o edifício educativo está desde sempre pronto a decretar a seus ocupantes; um olhar capaz, entretanto e em igual medida, de matricial modos de pensar e de agir sempre em estado de dissolução e recomposição.
Ressalve-se: o que aqui está em jogo não é algo exatamente da exortação escatológica, mas o desconfinamento radical de nossa capacidade de estranhar, ponto a ponto, tudo o que se apregoa como requisito, fundamento ou condição para que o mundo e a vida aconteçam. Estes, decerto, acabam por dispensá-los por completo.

E já que "tudo é intriga no nosso mundo sublunar", como ensina Paul Veyne (2009, p.29), resta-nos a tarefa ético-política de levar ao longe uma arte geral do dissenso, por meio da qual se abrissem espaço e vazão não apenas para a algaravia de sentidos que se perfilam nas intermitências do acontecimento educacional, mas, sobretudo, para a fortuidade e a indeterminação que contornam a experiência ético-estética que aí pode tomar lugar, desde que crivada por uma disposição aguerrida de esquiva e, concomitantemente, de reencontro íntimo, acalorado e desobstruído com o próprio tempo; reencontro consubstanciado em uma atitude radicalmente crítica aos modos de pensar e agir menos pretensiosos, de um lado, e mais recalcitrantes, de outro, quando em confronto com as novas gerações.

\section{Referências}

Aquino, J. G. (2012). Disjunção, dispersão e dissensão da educação contemporânea. In K. Saraiva, \& F. A. Marcello (Orgs.). Estudos culturais e educação: desafios atuais (pp. 138-156). Canoas: Ed. ULBRA.

Ball, S. (2013) Aprendizagem ao longo da vida, subjetividade e a sociedade totalmente pedagogizada. Educação, 36(2), 144-155.

Beillerot, J. (1985). A sociedade pedagógica. Porto: Rés.

Bernstein, B. (2003). A pedagogização do conhecimento: estudos sobre recontextualização. Cadernos de Pesquisa 120, 75-110.

Deacon, R.; Parker, B. (1998). Escolarização dos cidadãos ou civilização da sociedade?. In L. H. Silva (Org.). A escola cidadã no contexto da globalização (2. ed., pp.138-153). Petrópolis: Vozes.

Foucault, M. (2000). Em defesa da sociedade: Curso no Collège de France (1975-1976). São Paulo: Martins Fontes.

Foucault, M. (2004). Tecnologias de si. Verve, 6, 321-360.

Foucault, M. (2008a). Segurança, território, população: Curso no Collège de France (1977-1978). São Paulo: Martins Fontes. 
Foucault, M. (2008b). Nascimento da biopolítica: Curso no Collège de France (1978-1979). São Paulo: Martins Fontes.

Foucault, M. (2010). O governo de si e dos outros: curso no Collège de France (1982-1983). São Paulo: Martins Fontes.

Noguera-Ramírez, C. E. (2011). Pedagogia e governamentalidade ou Da Modernidade como uma sociedade educativa. Belo Horizonte: Autêntica.

Serres, M. (2000). Novas tecnologias e sociedade pedagógica: uma conversa com Michel Serres. Interface, 4(6), 129-142.
Smeyers, P., \& Depaepe, M. (Eds.). (2008). Educational research 3: the educacionalization of social problems. New York: Springer.

VeigaNeto, A. (2004). Algumas raízes da pedagogia moderna. In: M. C. Zorzo, L. D. Silva, \& T. Polenz (Orgs.). Pedagogia em conexão (pp. 65-83). Canoas: Ed. ULBRA.

Veyne, P. (2009). Foucault, o pensamento, a pessoa. Lisboa: Texto \& Grafia. 